\title{
Pengaruh Mailing Groups Sebagai Media Diskusi Dalam Motivasi Belajar Mahasiswa
}

\author{
Qurotul Aini, Untung Rahardja, Ruli Supriyati, Alfiah Khoirunisa
}

\author{
STMIK Raharja, Indonesia \\ Email: aini@raharja.info, untung@raharja.info, ruli@raharja.info, alfiah@raharja.info
}

\begin{abstract}
Abstrak
Pada era globalisasi saat ini, manajemen teknologi telah menyentuh setiap sendi kehidupan manusia. Perpaduan antara kedua faktor tersebut akan menjadi sebuah inovasi baru dalam manajemen dunia pendidikan. Pada Perguruan Tinggi Raharja, seluruh civitas akademika memiliki fasilitas yang berupa email resmi yaitu Rinfo yang berfungsi sebagai media komunikasi. Namun, belum terdapat wadah untuk melakukan manajemen diskusi antara mahasiswa dan juga dosen, sehingga proses diskusi pembelajaran dianggap belum efektif dan efisien karena masih dilakukan secara langsung. Oleh sebab itu, diperlukan adanya optimalisasi pemanfaatan RinfoApps yang digunakan sebagai media diskusi pembelajaran online. Mailing Groups merupakan salah satu fitur Google System yang dapat dimanfaatkan sebagai media formal untuk proses manajemen diskusi pembelajaran online. Dengan membuat forum yang disebut dengan milis kelas pada Mailing Groups, mahasiswa dan dosen dapat melakukan diskusi kapan saja dimana saja, mahasiswa dapat melakukan sharing mengenai bahan materi pembelajaran, serta dosen juga dapat memantau keaktifan berdiskusi mahasiswa, hal tersebut tentunya memiliki pengaruh penting bagi motivasi belajar mahasiswa. Didukung dengan 2 (dua) metode penelitian yaitu studi pustaka dan metode observasi. Hasil akhir dari penelitian yang telah dicapai yaitu terbentuknya sebuah media diskusi yang mudah diakses dimana dan kapan saja sehingga memungkinkan proses diskusi antara mahasiswa dan dosen menjadi lebih efektif dan efisien.
\end{abstract}

Kata kunci: Grup Mailing, Media Komunikasi, Siswa, Diskusi

\begin{abstract}
In the current era of globalization, technology management has touched every part of human life. The combination of these two factors will become a new innovation in the management of education. At Raharja College, the entire academic community has a facility in the form of an official e-mail, Rinfo, which functions as a communication medium. However, there is no place for discussion management between students and lecturers, so that the discussion process of learning is considered to be ineffective and inefficient because it is still done directly. Therefore, it is necessary to optimize the use of RinfoApps which is used as a discussion medium for online learning. Mailing Groups is one of the Google System features that can be used as a formal media for the online learning discussion management process. By creating a forum called the class mailing list on Mailing Groups, students and lecturers can discuss anytime, students can share about learning material, and lecturers can also monitor the activeness of student discussions, this certainly has an important influence on learning motivation college student. Supported by 2 (two) research methods, namely library research and observation methods. The final results of the research that has been achieved are the formation of a discussion media that is easily accessible anywhere and anytime so as to enable the discussion process between students and lecturers to be more effective and efficient.
\end{abstract}

Keywords: Mailing Groups, Media Communication, Students, Discussion

\section{PENDAHULUAN}

Pendidikan sudah seharusnya mengikuti perkembangan teknologi, bukan malah sebaliknya. Pendidikan beradaptasi dengan perkembangan teknologi yang semakin canggih dengan perpaduan antara pendidikan dan teknologi maka akan menciptakan sebuah inovasi baru [1]. Kedua faktor tersebut dapat saling berkaitan satu sama lainnya. Inovasi tersebut adalah metode iLearning yang diterapkan pada Perguruan Tinggi Raharja [2]. Terdapat beberapa jurusan dengan konsentrasi sudah menerapkan metode ini, yang mana konsentrasi tersebut merupakan unggulan di Perguruan Tinggi Raharja, sebab metode pembelajaran yang dilakukan mengimplementasikan metode iLearning dan perangkat iPad sebagai media belajar [3]. Metode iLearning diciptakan oleh Ir. Untung Rahardja pada tahun 2009, metode ini mengajak mahasiswa bukan hanya belajar, tapi juga bekerja, bermain dan berdoa.

Pada metode iLearning terdapat 10 pilar IT, salah satunya adalah Rinfo. Rinfo adalah merupakan email resmi yang digunakan oleh Perguruan Tinggi Raharja sebagai media komunikasi sekaligus alat bantu melakukan manajemen diskusi dalam proses pembelajaran [4]. Mengadaptasi dari Google for Education, maka terciptalah sebuah metode baru bernama Rinfo for Education atau dapat disebut RiDu [5]. Metode iLearning dimana Rinfo dijadikan sebagai media utama, yang terintegrasi dengan 10 pilar IT lainnya. Karena untuk mengakses 10 Pilar IT lainnya tersebut, dibutuhkan pendaftaran (register) menggunakan akun Rinfo. Manfaat dari penggunaan akun Rinfo tersebut sebagai akun resmi kampus, dapat dilihat dari segi keamanan yaitu akan mencegah orang yang berasal dari luar institut menyalah gunakan akses 10 Pilar IT di Perguruan Tinggi Raharja [6]. Dengan adanya Rinfo ini, maka terciptalah sebuah konsep baru bernama RiDu (Rinfo for Education), yaitu pembelajaran iLearning menggunakan email Rinfo sebagai media utama. Banyak Perguruan Tinggi yang masih menggunakan metode konvensional dalam melakukan komunikasi, seperti surat-menyurat, menulis dokumen, membuat pengumuman dan lain sebagainya [7]. Dengan adanya Rinfo ini, kita dapat memanfaatkan Rinfo Docs untuk menulis surat atau dokumen, dan membuat pengumuman dengan Rinfo Calendar. Selain itu, dengan adanya Rinfo ini diharapkan akan mendukung proses pembelajaran di perguruan tinggi, seperti diskusi di milis (Rinfo Group), saling berbagai (share) dokumen pembelajaran di Rinfo Docs, atau diskusi langsung menggunakan Rinfo Hangouts [8]. 
Pada penelitian yang sebelumnya dilakukan oleh Aris Martono, Padeli dan Rosalina Miliartha pada tahun 2016 yang berjudul "Rancang-Bangun Aplikasi Sistem Diskusi Pembelajaran Online Pada Perguruan Tinggi." Penelitian ini membahas mengenai forum diskusi online yang disajikan dalam bentuk web, yang nantinya sistem diskusi online ini di peruntukan kelas reguler atau non ilearning. Manfaat penelitian yaitu dapat mempermudah proses komunikasi pembelajaran antara dosen dan mahasiswa [9]. Penelitian selanjutnya oleh Agus Putranto dari Universitas Bina pada tahun 2012 yang berjudul "Perancangan Forum Diskusi Mobile Online Learning". Penelitian ini membahas tentang forum diskusi pada media Elearning disajikan dalam bentuk mobile. Salah satu fitur yang penting dalam kegiatan belajar mengajar adalah forum diskusi. Hasil dari penelitian ini yaitu mahasiswa dan dosen dapat dengan mudah mengakses forum diskusi dengan mengakses m-learning, mahasiswa juga dapat mengunduh bahan materi perkuliahan dan mendapatkan informasi seputar perkuliahan [10]. Penelitian selanjutnya oleh Dewi Immaniar Desrianti, Lusyani Sunarya, dan Dwi Fitri Permania pada tahun 2015 yang berjudul "Pemanfaatan Teknologi Komunikasi Dan Informasi (TIK) Pada Rhjfox Sebagai Forum Diskusi". Penelitian ini membahas tentang Forum Diskusi online yang diberi Nama Rhjfox yang digunakan sebagai wadah berkomunikasi dengan tujuan memberi pendapat, motivasi, solusi, dan informasi terkait dengan pembahasan yang sedang berlangsung. Dengan memanfaatkan Rhjfox, kegiatan berdiskusi dapat dilakukan dimana dan kapan saja asalkan terkoneksi dengan internet sehingga mahasiswa dan dosen dapat berdiskusi tanpa harus bertatap muka sehingga lebih efektif dan efisien [11].

\section{METODE PENELITIAN}

Terdapat 4 (empat) tahapan yang digunakan dalam melakukan penyusunan penelitian ini yaitu sebagai berikut:

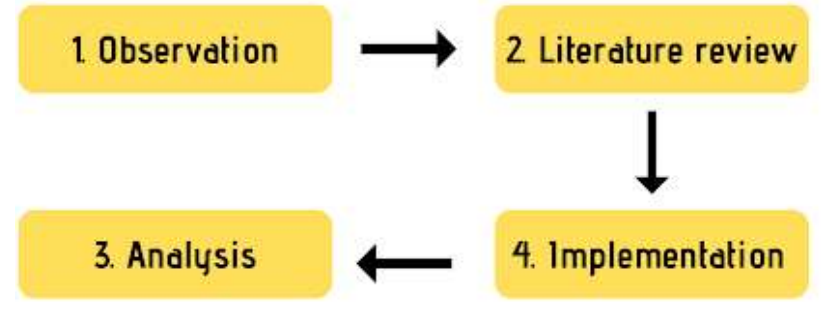

Gambar 1. Metode Penelitian

1. Metode Observasi

Metode observasi dilakukan dengan cara melakukan pengamatan langsung kepada proses berjalannya sebuah sistem. Tujuan observasi ini yaitu untuk mendeskripsikan setting yang di pelajari, aktivitas yang berlangsung, orang-orang yang terlibat dalam aktivitas dan makna dari perpekstif mereka terlibat dalam kejadian yang diamati tersebut [12]. Pada penelitian ini Observasi dijalankan secara langsung pada Perguruan Tinggi Raharja.

2. Metode Study Pustaka

Banyak penelitian yang sudah dilakukan sebelumnya mengenai Mailing Groups bisa dijadikan sumber data. Diantaranya beberapa buku dan penelitian yang dijadikan sumber pustaka, yaitu :

a. Penelitian yang dilakukan oleh Indri Handayani, Herrafika Kusumahati dan Alpiah Nurul Badriah dari Perguruan Tinggi Raharja pada tahun 2017 yang berjudul "Pemanfaatan Google Spreadsheet Sebagai Media Pembuatan Dashboard pada Official Site iFacility di Perguruan Tinggi”. Pada penelitian ini membahas mengenai penerapan dashboard pelaporan AC pada Official site iFacility dengan menggunakan salah satu fitur google yaitu Google Spreadsheet yang bisa dimanfaatkan untuk menampung data dan mengolah data untuk dijadikan sebuah informasi yang dibutuhkan. Tahapantahapan identifikasi Implementasi penelitian dilakukan dengan menggunakan metode observasi, wawancara terhadap divisi operasi, perbandingan sistem, perancangan prototype dan implementasi sistem ke dalam official site iFacility [13].

b. Penelitian yang dilakukan oleh Untung Rahardja, Qurotul Aini, dan Dian Mustika Putri dari Perguruan Tinggi Raharja pada tahun 2018 yang berjudul "Pemanfaatan Automated Email System (AEMS) Sebagai Media Notifikasi Penilaian Hasil Belajar" pada penelitian ini membahas perihal mutu pendidikan yang diterapkan Perguruan Tinggi memiliki sebab akibat dari evaluasi secara terintegrasi, berkala, tersusun dan dilakukan secara berkesinambungan. Sehingga, hal ini mendorong semua Perguruan Tinggi untuk terus berinovasi memberikan fasilitas pelayanan akademik yang baik kepada civitasnya. Khususnya dalam penyampaian informasi hasil penilaian pembelajaran mahasiswa, yang dituntut untuk tersampaikan dengan baik [14].

c. Penelitian yang dilakukan oleh Qurotul Aini, Rubin Hakita Irwin, Eka Marjayanti pada tahun 2017 dengan Judul "Notifikasi Pembelajaran iLearning Melalui Media Aplikasi iDu dengan Menggunakan Email Rinfo". Penelitian ini membahas mengenai sistem penyampaian informasi perkuliahan antara dosen dan mahasiswa secara online pada media aplikasi iDu melalui email Rinfo. Sehingga hal ini berguna agar 
penyampaian informasi antara mahasiswa dan dosen dapat tersampaikan dengan efisien, dimana saja, dan kapan saja [15].

d. Penelitian yang dilakukan oleh Untung Rahardja, Qurotul Aini, dan Nuke Puji Lestari Santoso pada tahun 2018 dengan judul penelitian "Pengintegrasian YII Framework Berbasis API pada Sistem Penilaian Absensi" yang menjelaskan bahwa sebuah Perguruan Tinggi memiliki beberapa kegiatan akademik contohnya kegiatan dalam pembelajaran atau bimbingan. Perguruan Tinggi Raharja memiliki email khusus bagi Pribadi Raharja yang platform nya sama seperti Gmail yang disebut email Rinfo. Rinfo atau biasa disebut email Raharja.info adalah bagian dari Tpi (Ten pilar IT learning) sebagai alat komunikasi berupa email resmi bagi pribadi raharja, maupun dosen juga staf [16].

e. Penelitian yang di lakukan oleh Chasfriati Filja, Mardhiah Fadly, dan Syefrida Yulina dari Politeknik Caltex Riau dalam bentuk laporan jurnal Aksara Komputer Terapan Vol.5 No.1 Tahun 2016 yang berjudul "Sistem Informasi Penilaian Partisipasi Mahasiswa Dalam Berdiskusi Secara Online Menggunakan Metode Content Analysis". Penelitian ini bertujuan untuk merancang dan membangun sistem informasi penilaian partisipasi mahasiswa dalam berdiskusi secara online. Metode yang digunakan dalam penelitian ini yaitu metode content analysis yaitu teknik penelitian dalam membuat kesimpulan yang valid berdasarkan isi dengan memperhatikan konteksnya. Jenis pengujian dalam penelitian ini menggunakan metode whitebox texting terhadap kode program QLF dan Rubric [17].

f. Penelitian yang dilakukan oleh Alwiyah dan Achmad Baihaki dari Universitas Wiraraja, Sumenep dengan judul penelitian "Penerapan Sistem Informasi Akuntansi Berbasis Komputer Dalam Pengambilan Keputusan Guna Meningkatkan Efektifitas Pendapatan Pada Lembaga Penyiaran Publik Radio Republik Indonesia (LPP RRI) Stasiun Sumenep" yang menjelaskan bahwa sistem informasi akuntansi berbasis komputer, maka dengan pemakaian sistem tersebut terutama didalam perusahaan jasa ini sangat relevan untuk menjadi sebuah sistem yang sangat sesuai dengan kebutuhan untuk lebih meningkatkan taraf modernisasi dalam pengambilan keputusan guna meningkatkan efisiensi pendapatan yang semaksimal mungkin dari produksinya ini [18].

Dari 6 (Enam) Literature Review yang sudah dijabarkan, banyak penelitian yang sudah dilakukan mengenai media diskusi online serta ada pula yang membahas forum diskusi pembelajaran online berbasis web, hingga pemanfaatan Rhjfox sebagai forum diskusi mahasiswa dan dosen, pembuatan fitur forum diskusi pada aplikasi mobile bahkan pembuatan sistem informasi untuk penilaian partisipasi mahasiswa dalam diskusi online. Namun dapat di simpulkan belum ada penelitian yang dilakukan mengenai pemanfaatan Mailing Groups sebagai media diskusi online yang digunakan oleh kelas iLearning di Perguruan Tinggi Raharja..

\section{ANALISA DAN PEMBAHASAN}

Terdapat 3 (tiga) perbedaan pada penelitian ini dari yang telah diuraikan di atas. Perbedaan pertama yaitu penelitian ini memanfaatkan salah satu fitur dari Google System yaitu Mailing Groups sedangkan dari ketiga penelitian di atas menggunakan website dan mobile application dalam media diskusinya. Perbedaan kedua yaitu media diskusi dirancang untuk digunakan oleh mahasiswa regular yang mana pada penelitian ini ditujukan untuk mahasiswa iLearning. Perbedaan ketiga yaitu untuk dapat melakukan diskusi mahasiswa hanya perlu membuka inbox Rinfo masing-masing sedangkan, pada penelitian sebelumnya mahasiswa harus mengunjungi website atau mempunyai mobile application terlebih dahulu untuk dapat melakukan diskusi.

Proses berdiskusi di dalam kelas dilakukan secara tatap muka memiliki 3 (tiga) permasalahan. Permasalahan yang pertama adalah mahasiswa dan dosen kesulitan dalam melakukan proses diskusi di luar kelas atau di luar jam perkuliahan karena belum adanya wadah yang dapat digunakan sebagai media diskusi. Permasalahan yang kedua adalah dosen kesulitan menyampaikan informasi baru secara cepat kepada seluruh mahasiswa, dan harus menyampaikan pesan satu persatu kepada mahasiswa. Permasalahan yang ketiga adalah dosen tidak bisa menilai keaktifan mahasiswa dalam berdiskusi secara langsung sehingga motivasi beajar mahasiswa menurun, khususnya untuk kelas iLearning karena dalam berdiskusi langsung dosen tidak mempunyai data-data mahasiswa mana yang aktif melakukan diskusi jika tidak mencatatnya secara manual sehingga dosen tidak bisa menilai keaktifan diskusi mahasiswa.

Mailing Groups sendiri sudah terintegrasi dengan Rinfo sehingga pengguna tidak perlu lagi mendaftar untuk dapat terhubung dengan Milis Groups. Di dalam Mailing Groups kita dapat membuat sebuah milis kelas yang berisikan akun Rinfo seluruh mahasiswa dan dosen yang ada pada sebuah kelas agar seluruh alamat Rinfo tersebut terhimpun dalam sebuah milis grup atau kelompok diskusi dalam sebuah kelas. Dalam mengakses Mailing Groups pun sangat mudah, yaitu dengan login Rinfo dan memasukan nama pengguna dan kata sandi, setelah itu sudah dapat terhubung dengan grup diskusi. Untuk melakukan diskusi pada Mailing Groups, kita hanya perlu login Rinfo dan grup diskusi sudah dapat diakses tanpa harus login berulang kali.

Penggunaan Mailing Groups pada suatu kelas dapat menjadi sebuah wadah atau komunitas formal untuk proses diskusi antara mahasiswa dan dosen di luar jam perkuliahan sehingga proses diskusi dapat diakses dimana saja dan dan saja tanpa terhambat ruang dan waktu. Manfaat lain dari Mailing Groups yaitu anggota dalam sebuah 
grup (dosen atau mahasiswa) dapat memberikan informasi serta mendapatkan informasi secara cepat, akurat, dan sesuai kebutuhan. Dengan menggunakan Mailing Groups, dosen dapat juga memantau keaktifan diskusi mahasiswa dalam sebuah statistik yang tersedia di dalam Mailing Groups yang dapat diakses dalam menu about. Pada menu ini dosen dapat melihat keaktifan dalam sebuah milis kelas dari banyaknya jumlah pesan yang di kirimkan oleh mahasiswa yang ada pada milis kelas tersebut.

\section{IMPLEMENTASI}

Pemanfaatan Mailing Groups saat ini telah dipakai sebagai wadah berdiskusi atau komunitas formal (forum) pada kelas iLearning ataupun untuk berbagai grup diskusi yang ada di perguruan tinggi raharja, contohnya sebagai wadah diskusi mahasiswa grup bimbingan TimUR 6. Selain sebagai media diskusi, Mailing Groups dapat digunakan untuk menilai keaktifan diskusi anggotanya dengan melihat statistik laporan aktivitas yang telah disediakan Mailing Groups.

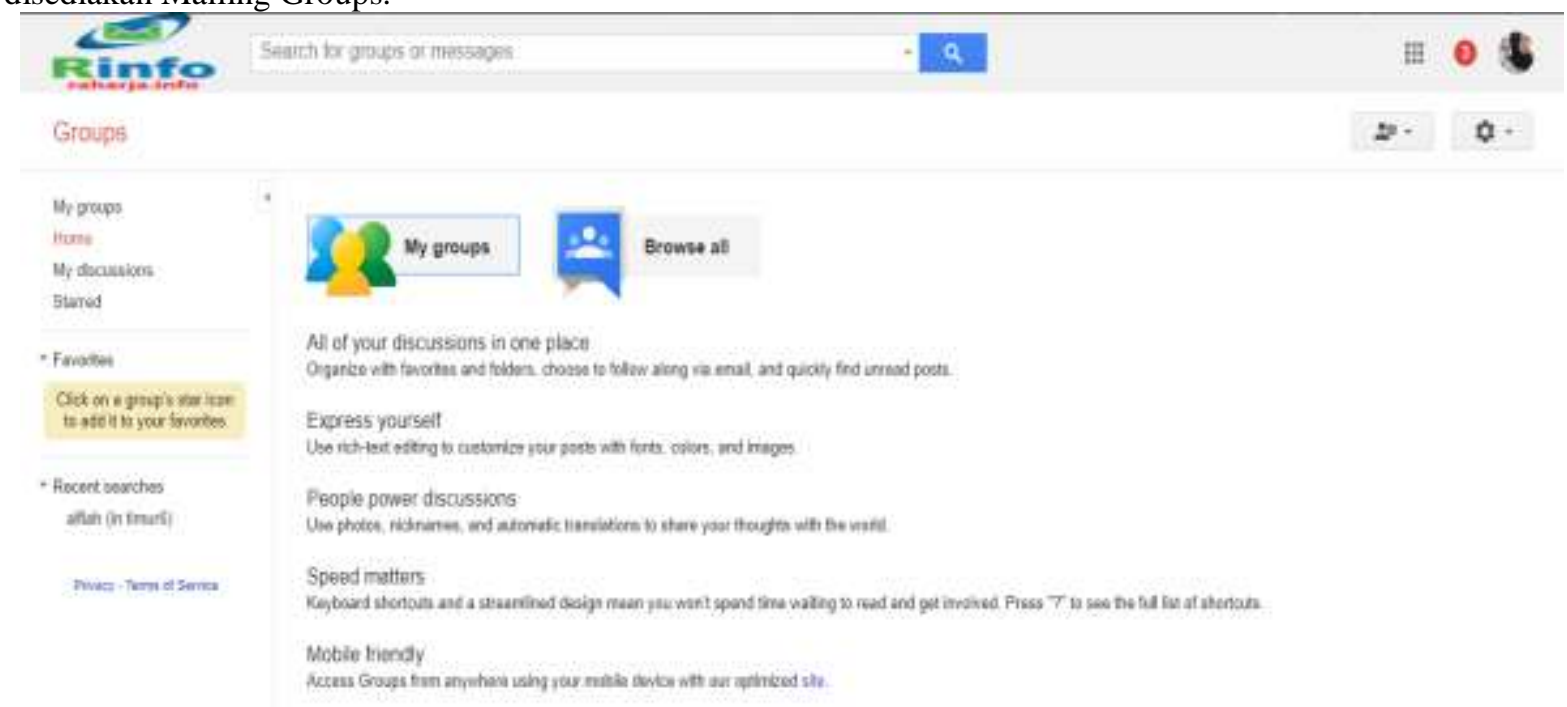

Gambar 2. Menu Home pada Mailing Groups

Merupakan tampilan utama / Home pada Mailing Groups. Pada sisi kiri terdapat menu My Group, Home, My Discussion, dan Starred. Pada sisi kanan terdapat foto dari user yang melakukan login dan juga di bawahnya terdapat menu Setting dan menu untuk terhubung dengan RinfoApps lainnya.

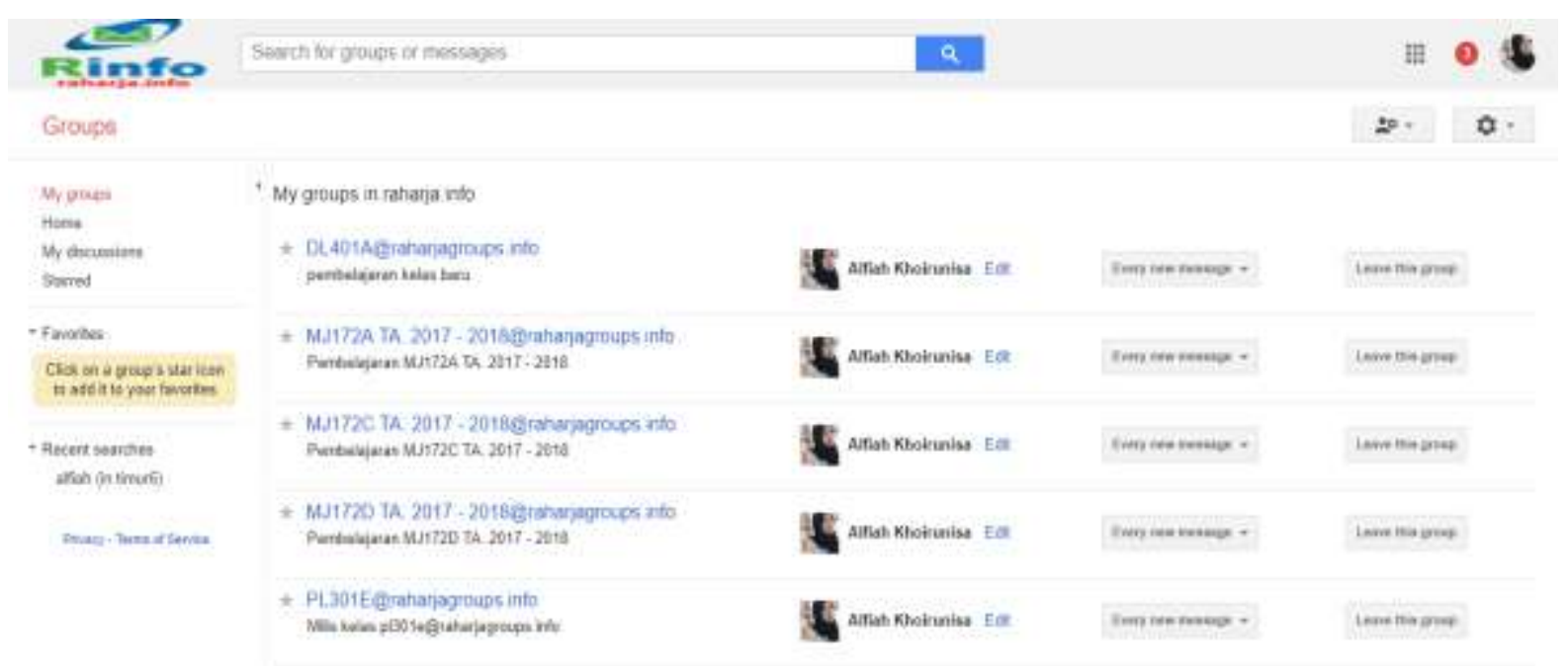

Gambar 3. Menu My Groups

Merupakan tampilan halaman My Groups . Dimana mahasiswa yang telah Login dapat melihat daftar grup dimana mahasiswa tersebut menjadi anggotanya. Pada halaman ini kita dapat membuka grup diskusi dengan meng-klik nama grup yang ingin dibuka. 


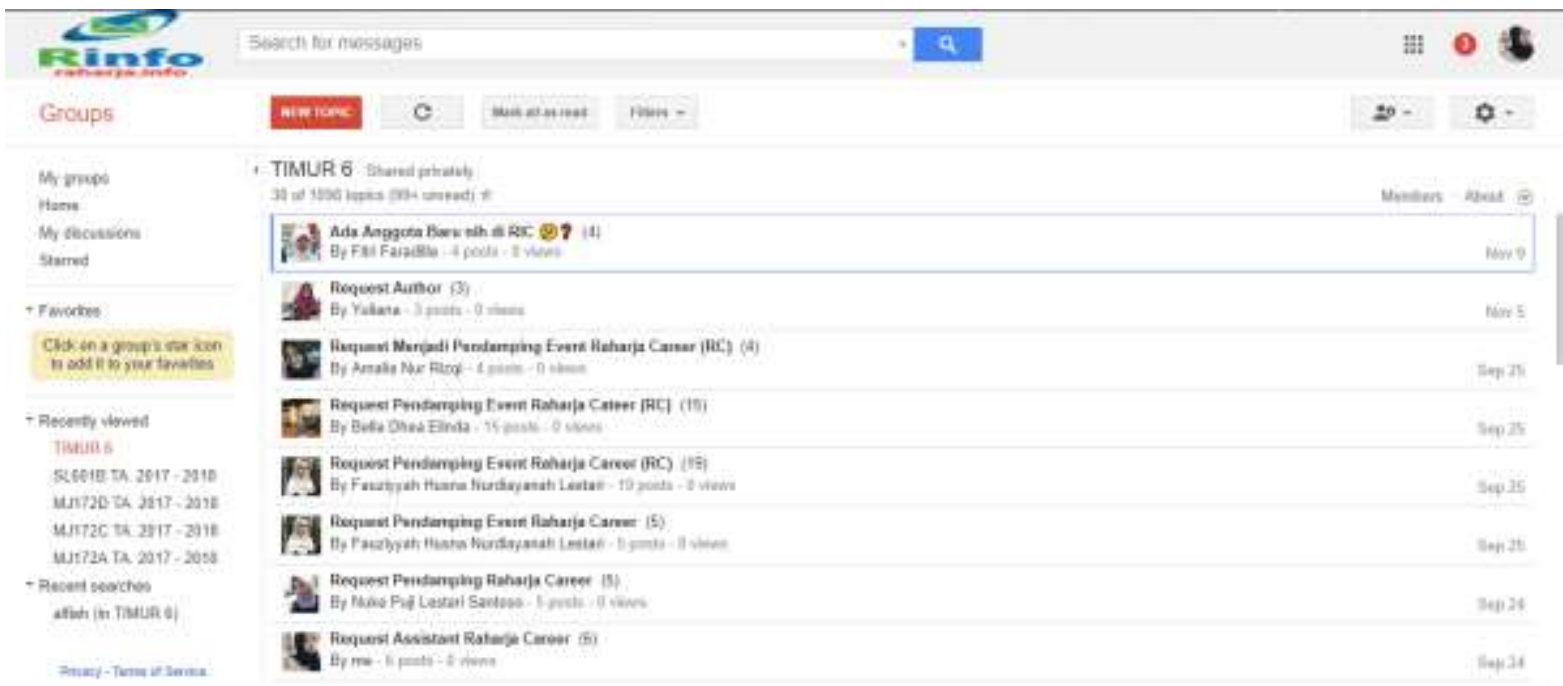

Gambar 4. Halaman Milis Rinfo

Merupakan tampilan utama halaman diskusi pada Milis Rinfo bimbingan TimUr 4. Pada halaman ini terdapat nama pengirim pesan dan subjek dari pesan yang dikirimkan . Pada halaman diskusi ini juga bisa di lihat seberapa banyak respon yang di dapatkan dari pesan yang sudah dikirimkan dan juga tanggal pengiriman respon terakhir yang bisa di lihat pada bagian kanan subjek diskusi.

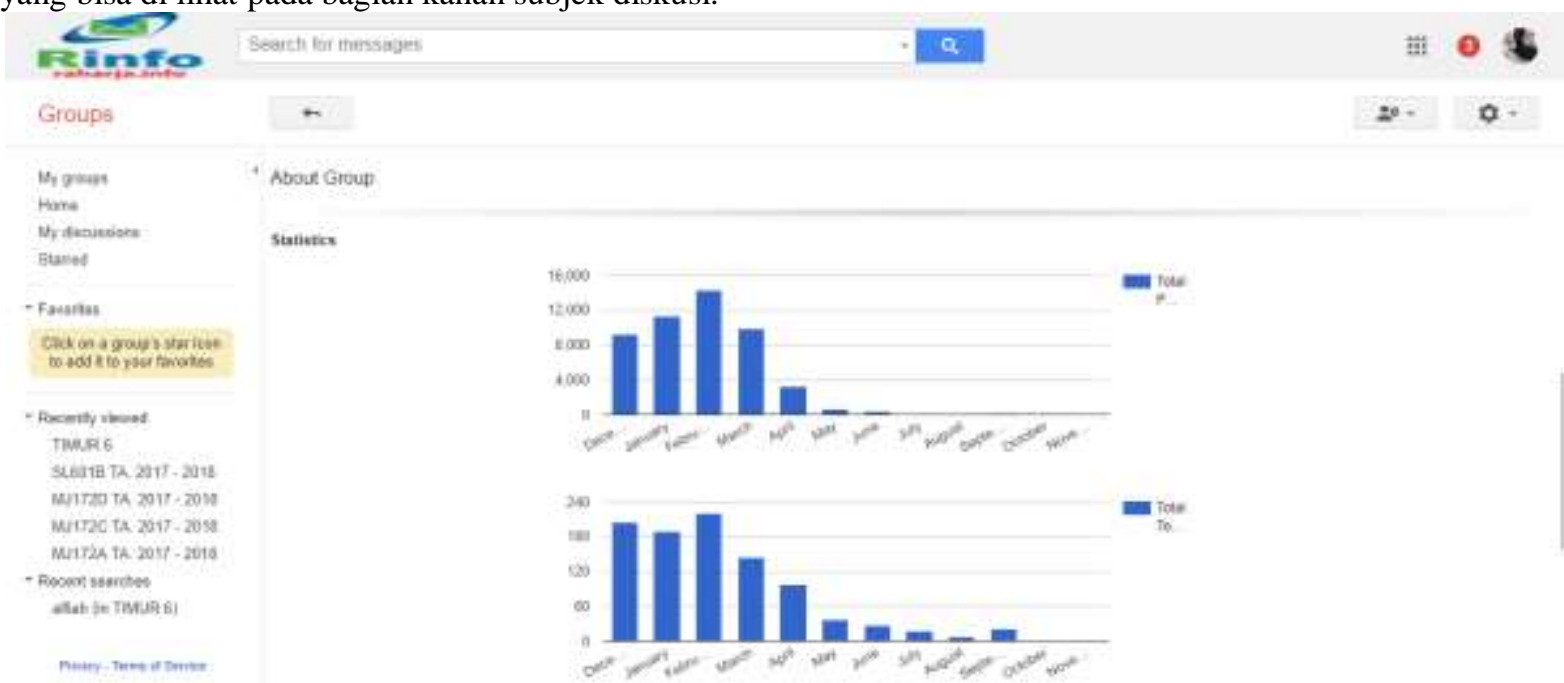

Gambar 5. Statistik Mailing Groups

erupakan tampilan halaman yang dapat menampilkan statistik keaktifan anggota dalam sebuah milis grup. Dengan adanya menu About Group, dapat membantu dosen untuk melihat sejauh mana keaktifan mahasiswa dalam berdiskusi karena dalam menu tersebut terdapat jumlah postingan/pesan yang sudah dikirimkan yang dipisahkan menjadi dua menu yaitu : Most Actived Poster keseluruhan dan Most Actived Poster per-bulan.

Grafik Statistik

1. Dengan adanya implementasi ini proses berdiskusi pembelajaran dosen dan mahasiswa dapat di lakukan secara online, dan bisa dilakukan dimana saja dan kapan saja di luar jam perkuliahan.

2. Dengan adanya implementasi ini mahasiswa dan dosen tidak perlu lagi mendaftar untuk dapat menjadi anggota sebuah grup diskusi, melainkan hanya login menggunakan Rinfo maka sudah dapat terhubung dengan grup diskusi.

3. Dengan adanya implementasi ini memudahkan dosen dalam menyampaikan informasi secara cepat dan akurat, sehingga bisa di terima cepat pula oleh mahasiswa.

4. Dengan adanya implementasi ini, memungkinkan dosen untuk sharing mengenai bahan materi pembelajaran yang disimpan dalam Google drive agar bisa di unduh oleh mahasiswa dalam suatu kelas.

\section{KESIMPULAN}

Pada Perguruan Tinggi Raharja, kegiatan diskusi antara mahasiswa dan dosen masih belum berkembang karena diskusi masih di lakukan secara langsung atau tatap muka sehingga proses diskusi pembelajaran kurang maksimal, 
karena diskusi hanya berlangsung selama perkuliahan berlangsung. Dengan adanya pemanfaatan dari Mailing Groups diharapkan proses diskusi pembelajaran menjadi lebih efektif dan efisien dimana proses berdiskusi dapat di akses dimana dan kapan saja, sehingga memudahkan mahasiswa mendapatkan informasi terbaru mengenai perkuliahan. Pemanfaatan Mailing Groups ini di harapkan dapat menjadi wadah diskusi formal pada kelas iLearning sehingga dapat meningkatkan kualitas informasi pada Perguruan Tinggi Raharja. Adapun kelebihan yang di dapat dengan menggunakan Mailing Groups yaitu bersifat Online, dapat diakses dimana dan kapan saja, tidak perlu mendaftar jika ingin masuk ke Grup diskusi, hanya perlu memiliki akun Rinfo, dapat terhubung dengan RinfoApps lainnya, mempermudah interaksi antara mahasiswa dan dosen di luar jam perkulihaan dan yang terakhir memudahkan dosen sharing materi perkuliahan.

\section{REFERENCES}

[1] Aini, Q., Graha, Y. I., \& Zuliana, S. R. (2017). Penerapan Absensi QRCode Mahasiswa Bimbingan Belajar pada Website berbasis YII Framework. Sisfotenika, 7(2), 207-218.

[2] Rahardja, U., Aini, Q., \& Thalia, M. B. (2018). Penerapan Menu Konfirmasi Pembayaran Online Berbasis Yii pada Perguruan Tinggi. Creative Information Technology Journal, 4(3), 174-185.

[3] Rahardja, U., Harahap, E. P., \& Pratiwi, D. I. (2018). Pemanfaatan RinfoSheet Sebagai Media Informasi Laporan Penjualan Barang pada Raharja Internet Cafe. Jurnal Ilmiah Teknologi Informasi Asia, 12(1), 65-74.

[4] Rahardja, U., Aini, Q., Ariessanti, H. D., \& Khoirunisa, A. (2018). Pengaruh Gamifikasi pada iDu (iLearning Education) dalam Meningkatkan Motivasi Belajar Mahasiswa. Nusantara Journal of Computers and its Applications, 3(2).

[5] Sunarya, P. A., Nurhaeni, T., \& Haris, H. (2017). Bank Reconciliation Process Efficiency Using Online Web Based Accounting System 2.0 in Companies. Aptisi Transactions of Management (ATM), 1(2), 131-136.

[6] Rahardja, U., Harahap, E. P., \& Dewi, S. R. (2019). The Strategy of Enhancing Article Citation and H-Index on SINTA to Improve Tertiary Reputation. TELKOMNIKA (Telecommunication Computing Electronics and Control), 17(1).

[7] Rahardja, U. (2009, May). Artificial informatics. In Industrial Electronics and Applications, 2009. ICIEA 2009. 4th IEEE Conference on (pp. 3064-3067). IEEE.

[8] Aini, Q., Rahardja, U., Moeins, A., \& Wardani, A. M. (2018). Penerapan Data Market Query (DMQ) pada Sistem Penilaian Berbasis Yii Framework. InfoTekJar: Jurnal Nasional Informatika dan Teknologi Jaringan, 3(1), 26-31.

[9] Martono, A. (2016). RANCANG-BANGUN APLIKASI SISTEM DISKUSI PEMBELAJARAN ON-LINE PADA PERGURUAN TINGGI. CCIT Journal, 9(2), 179-190.

[10] Putranto, A. (2012). Perancangan forum diskusi mobile online learning. ComTech: Computer, Mathematics and Engineering Applications, 3(2), 860-871.

[11] Desrianti, D. I., \& Parmania, D. F. (2015). PEMANFAATAN TEKNOLOGI INFORMASI DAN KOMUNIKASI (TIK) PADA RHJFOX SEBAGAI FORUM DISKUSI. CCIT Journal, 8(3), 147-164.

[12] Rahardja, U., Aini, Q., \& Khoirunisa, A. (2018). Monitoring Kinerja User Akuntan Menggunakan Dashboard Pada Web Based Accounting Online di Perguruan Tinggi. SATIN-Sains dan Teknologi Informasi, 4(2), 58-62.

[13] Handayani, I., Kusumahati, H., \& Badriah, A. N. (2017). Pemanfaatan Google Spreadsheet Sebagai Media Pembuatan Dashboard pada Official Site iFacility di Perguruan Tinggi. Sisfotenika, 7(2), 177-186.

[14] Rahardja, U., Aini, Q., \& Putri, D. M. (2018). Pemanfaatan Automated Email System (AEMS) Sebagai Media Notifikasi Penilaian Hasi Belajar. SENSITEK, 1(1), 49-54.

[15] Aini, Q., Irwin, R. H., \& Marjayanti, E. (2017). Notifikasi Pembelajaran iLearning Melalui Media Aplikasi iDu dengan Menggunakan E-mail Rinfo. Technomedia Journal, 1(2), 1-12.

[16] Rahardja, U., Aini, Q., \& Santoso, N. P. L. (2018). Pengintegrasian YII Framework Berbasis API pada Sistem Penilaian Absensi. SISFOTENIKA, 8(2), 140-152.

[17] Filja, C., Fadli, M., \& Yulina, S. (2016). Sistem Informasi Penilaian Partisipasi Mahasiswa dalam Berdiskusi Secara Online Menggunakan Metode Content Analysis. Jurnal Aksara Komputer Terapan, 5(1).

[18] Alwiyah, A., \& Baihaki, A. (2012). Penerapan Sistem Informasi Akuntansi Berbasis Komputer Dalam Pengambilan Keputusan Guna Meningkatkan Efektifitas Pendapatan Pada Lembaga Penyiaran Publik Radio Republik Indonesia (Lpp Rri) Stasiun Sumenep. AKRUAL: Jurnal Akuntansi, 4(1), 1-18.

[19] Rahardja, U., Aini, Q., Azizah, N., \& Santoso, N. P. L. (2018). Efektivitas Akuntansi Online dalam Menunjang Proses Rekonsiliasi. Nusantara Journal of Computers and its Applications, 3(2).

[20] Guritno, S., \& Rahardja, U. (2011). Theory and Application of IT Research: Metodologi Penelitian Teknologi Informasi. Penerbit Andi.

[21] Rahardja, U., Aini, Q., \& Khoirunisa, A. (2017). Implementasi Business Intelligence Menggunakan Highchart pada Sistem Penilaian Absensi berbasis YII Framework. CSRID (Computer Science Research and Its Development Journal), 9(2), 115-124. 